\title{
Endogenous benzodiazepine-like compounds and diazepam binding inhibitor in serum of patients with liver cirrhosis with and without overt encephalopathy
}

R Avallone, M L Zeneroli, I Venturini, L Corsi, P Schreier, M Kleinschnitz, C Ferrarese, F Farina, C Baraldi, N Pecora, M Frigo, M Baraldi
Cattedra di Semeiotica e Metodologia Medica, Università di Modena, Modena, Italy M L Zeneroli

I Venturini

F Farina

C Baraldi

Lehrstuhl für Lebensmittelchemie, Universität Würzburg, Würzburg, Germany P Schreier

M Kleinschnitz

Clinica Neurologica, Università di Milano (Monza), Italy

C Ferrarese

N Pecora

M Frigo

Dipartimento di Scienze

Farmaceutiche, Università di Modena M Baraldi

R Avallone

L Corsi

Correspondence to: Professor Maria Luisa Zeneroli, Cattedra di Semeiotica e Metodologia Medica, Dipartimento di

Medicina Interna, Università di Modena, Via del pozzo

71-41100, Modena, Italy.

Accepted for publication 18 December 1997

\begin{abstract}
BackgroundlAim-Despite some controversy, it has been suggested that endogenous benzodiazepine plays a role in the pathogenesis of hepatic encephalopathy. The aim of the present study was to evaluate the concentrations of endogenous benzodiazepines and the peptide, diazepam binding inhibitor, in the blood of patients with liver cirrhosis with and without overt encephalopathy, and to compare these levels with those of consumers of commercial benzodiazepines.

Subjects-Normal subjects (90), benzodiazepine consumers (14), and cirrhotic patients (113) were studied.

Methods-Endogenous benzodiazepines were measured by the radioligand binding technique after high performance liquid chromatography (HPLC) purification. The presence of diazepam and $\boldsymbol{N}$-desmethyldiazepam was assayed by HPLC-electrospray tandem mass spectrometry. Diazepam binding inhibitor was studied in serum by radioimmunoassay.

Results-Endogenous benzodiazepines were below the limit of detection in $7 \%$ of patients with encephalopathy. When detectable, their levels were at least comparable with those of benzodiazepine consumers and correlated with the liver dysfunction but not the stage of encephalopathy. Serum levels of diazepam binding inhibitor tended to decrease when endogenous benzodiazepines levels increased.

Conclusions-Endogenous benzodiazepines may accumulate in patients with liver cirrhosis during the course of the disease, and the phenomenon appears to be independent of the presence or absence of encephalopathy.

(Gut 1998;42:861-867)
\end{abstract}

Keywords: benzodiazepine consumers; diazepam binding inhibitor; endogenous benzodiazepines; liver cirrhosis; overt hepatic encephalopathy

Hepatic encephalopathy is one of the major complications of liver cirrhosis, and it is a component of fulminant hepatic failure characterised by impairment of the central nervous system, which is believed to develop from increased tone of the inhibitory $\gamma$-aminobutyric acid $\left(\mathrm{GABA}_{\mathrm{A}}\right)$ receptor system (for reviews, ${ }^{1-3}$ ).
The involvement of this receptor system in overt hepatic encephalopathy (OHE), discovered in the 1980 s during studies on $\mathrm{GABA}_{\mathrm{A}}$ receptors in the brain of animals with $\mathrm{OHE}$, was considered likely when specific benzodiazepine receptor antagonists were shown to revert the symptoms of encephalopathy in animal models ${ }^{4}$ and in patients. ${ }^{56}$ Later, the observation of an increased presence of endogenous benzodiazepine receptor ligands (BZDs) in animals and patients with $\mathrm{OHE}^{7-13}$ suggested that this phenomenon may contribute to the enhancement of GABAergic neurotransmission. ${ }^{14}$ We cannot exclude, however, the possibility that compounds such as ammonia $^{1315}$ or neurosteroids ${ }^{16}$ contribute to the above mentioned increased functional activity of the $\mathrm{GABA}_{\mathrm{A}}$ receptor system. BZDlike compounds and ammonia may potentiate inhibitory GABAergic neurotransmission by acting synergistically. ${ }^{17}$

The endogenous receptor ligands found in blood and brain during $\mathrm{OHE}^{79}$ were called BZD-like substances since they are a mixture of the halogenated 1,4-benzodiazepines (such as diazepam) and non-halogenated BZDs (called "endozepines"). Although the chemical structure of the endozepines is not yet fully characterised, it is fair to surmise that they contribute to OHE.

Halogenated BZDs are naturally present in several plants and vegetables, ${ }^{18}$ in brain tissues of different animal species and in man. ${ }^{19}$ Their sources have not yet been clarified, but the observation that they are present in human brain samples stored since $1940^{20}$ indicates that they do not derive from environmental pollution with synthetic BZDs, which have been produced commercially since 1959. These compounds and their precursors are components of our diet. ${ }^{18}$ An exogenous biosynthetic pathway for the production of such compounds cannot, however, be excluded since we recently showed that a reduction in the intestinal bacterial flora caused by a non-absorbable antibiotic partially decreases the levels of these compounds in the blood. ${ }^{21}$

Other endogenous BZDs such as the neuropeptide called diazepam binding inhibitor (DBI) and its metabolite, the octadecaneuropeptide, which decreases GABA $_{A}$ neurotransmission, ${ }^{22}$ have been found to be increased in the cerebrospinal fluid of patients with $\mathrm{OHE}^{23}$ and in brain regions of rats with portacaval anastomosis. $^{24}$ 
Table 1 Patient characteristics

\begin{tabular}{|c|c|c|c|c|c|}
\hline & \multirow[b]{2}{*}{ Controls } & \multicolumn{3}{|c|}{ Liver cirrhosis } & \multirow[b]{2}{*}{ BZD comsumers } \\
\hline & & $A$ & $B$ & $C$ & \\
\hline No & 90 & 33 & 41 & 39 & 14 \\
\hline Men & 46 & 18 & 28 & 30 & 3 \\
\hline Women & 44 & 15 & 13 & 9 & 11 \\
\hline Age (y) (mean (SD)) & $63(9)$ & $59(9)$ & $57(11)$ & $50(11)$ & $65(4)$ \\
\hline \multicolumn{6}{|l|}{ Aetiology of cirrhosis } \\
\hline Viral & - & 22 & 27 & 28 & - \\
\hline Alcoholic & - & 6 & 11 & 6 & - \\
\hline Viral + alcoholic & - & 5 & 3 & 5 & - \\
\hline \multicolumn{6}{|c|}{ Overt encephalopathy (stage) } \\
\hline 0 & - & 33 & 16 & 10 & - \\
\hline I & - & - & 16 & 6 & - \\
\hline II & - & - & 9 & 10 & - \\
\hline III & - & - & - & 8 & - \\
\hline IV & - & - & - & 5 & - \\
\hline
\end{tabular}

A-C, functional status of the liver classified according to Child-Pugh.

Since few studies have been performed on endogenous circulating BZDs in patients with OHE due to fulminant hepatic failure ${ }^{13}$ or liver cirrhosis, ${ }^{79}{ }^{10}$ the aim of the present study was to $(a)$ evaluate the concentrations and nature of BZD-like compounds in the plasma of patients with liver cirrhosis with and without OHE, $(b)$ compare the levels found in liver cirrhotic patients with those present in the plasma of consumers of commercial BZDs in order to estimate their pharmacological relevance, and (c) study the levels of DBI in both the patients and BZD consumers, bearing in mind that little is known about the mutual interaction of BZD compounds and DBI at the periphery.

\section{Methods}

SUBJECTS (TABLES 1 AND 2)

We studied 113 patients with liver cirrhosis and 90 normal subjects, who appeared to be free of commercial BZD medication for at least three months as verified by patient, family, and medication records. Moreover 14 normal subjects who were habitual consumers of commercial BZDs were included in the study. The diagnosis of liver cirrhosis was based on biochemical tests and liver biopsy. Fifty nine patients showed no evidence of OHE while the other 54 showed different stages of impaired mental status. The stage of OHE was evaluated on the basis of electroencephalographic pattern. ${ }^{25}$ This test allowed the classification of the cirrhotic patients into the following categories: 59 with stage 0,22 with stage I, 19 with stage II, eight with stage III, and five with stage IV. The functional status of the liver was clinically classified according to the Child-Pugh classification. ${ }^{26}$ Table 1 gives the characteristics of the patients included in the study, and table 2 contains laboratory data.

The 14 regular consumers of BZDs, who used diazepam $2 \mathrm{mg}$ per day or lorazepam 2.5 mg per day as sedatives, had normal liver and kidney function.

Table 2 Laboratory data on patients with liver cirrhosis

\begin{tabular}{lllll}
\hline Child-Pugh class & $\begin{array}{l}\text { Bilirubin } \\
(\mu \mathrm{mol} / \mathrm{l})\end{array}$ & $\begin{array}{l}\text { Prothrombin time } \\
(\%)\end{array}$ & $\begin{array}{l}\text { Albumin } \\
(\mathrm{g} / \mathrm{l})\end{array}$ & $\begin{array}{l}\text { Ammonia } \\
(\mu \mathrm{mol} / \mathrm{l})\end{array}$ \\
\hline $\mathrm{A}$ & $15(8)$ & $75(10)$ & $37(3)$ & $33(13)$ \\
$\mathrm{B}$ & $34(29)$ & $55(9)$ & $30(5)$ & $98(44)$ \\
C & $97(61)$ & $40(10)$ & $28(2)$ & $84(46)$ \\
\hline
\end{tabular}

Values are mean (SD). Normal values: bilirubin 2-18 $\mu \mathrm{mol} / 1$; prothrombin time $80-100 \%$; albu$\min 3-5 \mathrm{~g} / \mathrm{l}$; venous ammonia $4-26 \mu \mathrm{mol} / 1$.
The serum obtained from all patients was stored at $-80^{\circ} \mathrm{C}$ until used and individually processed for the assay of BZDs and DBI. The study was carried out with the approval of the local ethical committee.

\section{QUANTIFICATION OF ENDOGENOUS BZD-LIKE} COMPOUNDS

As previously described, ${ }^{9}$ aliquots of all the serum samples $(1 \mathrm{ml})$ were acidified with acetic acid $(1 \mathrm{M})$, and centrifuged at $3000 \mathrm{~g}$ for ten minutes. The supernatant was passed through previously washed Sep-Pak $\mathrm{C}_{18}$ cartridges (Millipore, Medford, MA, USA). The material was eluted from Sep-Pak with acetonitrile/ $0.1 \%$ trifluoroacetic acid (TFA) and then lyophilised. The lyophilised samples were reconstituted with $1 \mathrm{ml}$ water, and aliquots $(200 \mu \mathrm{l})$ were chromatographed in duplicate at $0.8 \mathrm{ml} / \mathrm{min}$ on a LiChrospher $100 \mathrm{RP}-18$ column $(250 \times 4.0 \mathrm{~mm} ; 5 \mu \mathrm{m})$ equilibrated with $80 \%$ water $/ 0.1 \%$ TFA and $20 \%$ acetonitrile. Absorbance was monitored at 230 $\mathrm{nm}$. Samples were chromatographed using a water $/ 0.1 \%$ TFA and acetonitrile gradient at $0.5 \%$ per minute from 20 to $58 \%$ acetonitrile. Seventy five fractions (one per minute) from each sample were collected, lyophilised, and reconstituted with water before radioreceptor assay. Known concentrations of diazepam, $\mathrm{N}$-desmethyldiazepam, oxazepam, lorazepam, delorazepam, and 2'-chlordiazepam were run in parallel with the plasma samples.

Unless otherwise indicated, all reagents were obtained from Sigma Chemical Co. and were all high performance liquid chromatography (HPLC) grade. All the fractions were then tested for their ability to inhibit $\left[{ }^{3} \mathrm{H}\right]$ flunitrazepam (1 $\mathrm{nM}$; specific activity 87 $\mathrm{Ci} / \mathrm{mmol}$; NEN, Boston, MA, USA) binding to rat cerebellar membrane preparations, which are a source of BZD receptors, ${ }^{9}$ and containing 180-200 $\mu \mathrm{g}$ protein $/ 100 \mu \mathrm{l}$ measured by Bradford's method. ${ }^{27}$ Data were expressed as diazepam equivalents (DE) based on extrapolation from standard displacement curves generated using diazepam. The total concentration of BZD-like compounds present in each serum was calculated by determining the DE derived from the displacement activity of any single peak and then summing the values of all peaks.

Since the chemical identities of all the components of the BZD-like material are not known, their extraction efficiencies could not be determined. The limit of detection of diazepam by $\left[{ }^{3} \mathrm{H}\right]$ flunitrazepam binding was 2 nmol DE/1 with a coefficient of variation of 0.52 . Assays were performed in triplicate and variations from the mean were less than $15 \%$.

DETERMINATION OF 1,4-BENZODIAZEPINES BY HPLC-ELECTROSPRAY TANDEM MASS SPECTROMETRY (HPLC-ESI-MS-MS) HPLC-ESI-MS-MS was carried out by the method of Kleinschnitz et al. ${ }^{28}$ The analysis was performed using a triple stage quadrupole TSQ 7000 LC-MS-MS system with electrospray interface (Finnigan MAT, Bremen, Germany). Data acquisition and mass spectrometric evaluation were conducted on a Personal 


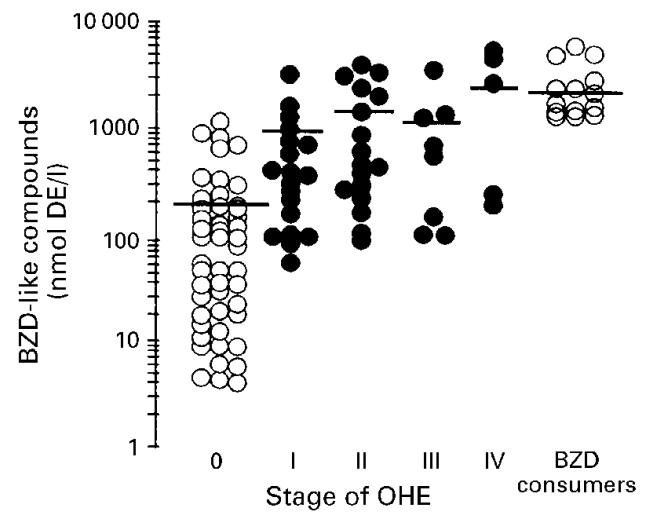

Figure 1 Serum levels of benzodiazepine (BZD)-like compounds measured by the radioligand binding technique after HPLC purification in liver cirrhotic patients without encephalopathy (stage 0), with encephalopathy (OHE; stages I, II, III and IV) and in BZD consumers. The horizontal bar represents the mean value. Kruskal-Wallis one way analysis of variance shows a significant difference between groups $(p<0.0001)$. The Mann-Whitney U test adjusted using the Bonferroni correction shows that patients with liver cirrhosis without $O H E$ (stage 0) differed from all the patients with $O H E(p<0.001)$. The levels found in patients with $O H E$ stages $I, I I, I I I$, and $I V$ were not different from each other and not different from the levels found in BZD consumers.

DECstation 5000/33 (Digital Equipment, Unterföhring, Germany) and ICIS 8.1 software (Finnigan MAT). For HPLC, an Applied Biosystem 140B Solvent Delivery System (Applied Biosystems, Foster City, CA, USA) equipped with two $10 \mathrm{ml}$ syringes and a LiChrospher $60-\mathrm{RP}$ select $\mathrm{B}$ column $(100 \times 2.0 \mathrm{~mm}$ internal diameter; $5 \mu \mathrm{m}$; Knauer, Berlin, Germany) was used. Aliquots of the lyophilised samples were redissolved in $100 \mu \mathrm{l}$ methanol/water/ acetonitrile (1:1:1, by vol.). Separations were performed using a linear gradient. Solvent A was $0.1 \%$ TFA in water, and solvent $B$ was acetonitrile. The gradient program was: $0-10$ $\min , 20-80 \%$ solvent $\mathrm{B}$. The loop injection was $5 \mu \mathrm{l}$ and the solvent flow was set to $200 \mu \mathrm{l} / \mathrm{min}$. The mass spectrometer was operated in the selected reaction monitoring mode, with argon at a pressure of $0.27 \mathrm{~Pa}$ as collision gas. Selected ion pairs for the simultaneous experiment were (offset voltages in brackets): $\mathrm{m} / \mathrm{z}$ $217 / 140(-30 \mathrm{eV})$ for $N$-desmethyldiazepam and $m / z 285 / 257(-30 \mathrm{eV})$ for diazepam. The ion pairs represent the protonated molecular ion $[\mathrm{M}+\mathrm{H}]^{+}$and the most abundant product ion for each of the BZDs. The temperature of the heating capillary was $250^{\circ} \mathrm{C}$. The electrospray capillary was set to $5 \mathrm{kV}$ and the electron multiplier voltage was set to $2.3 \mathrm{kV}$. A sheath gas pressure of $73 \mathrm{~Pa}$ and an auxiliary gas flow of 5 litres/min were applied to support the droplet formation. Nitrogen served both as sheath and auxiliary gas. With this method a detection limit of $1.75 \mathrm{pmol} / 1$ for $\mathrm{N}$-desmethyldiazepam and diazepam at a signal-to-noise ratio of 2:1 was reached.

QUANTIFICATION OF DBI

The level of DBI-like immunoreactivity (DBILI) in serum was assayed in 16 controls, in 19 patients with liver cirrhosis without $\mathrm{OHE}$, in 12 patients with liver cirrhosis with OHE, and in eight BZD consumers. To extract DBI and to

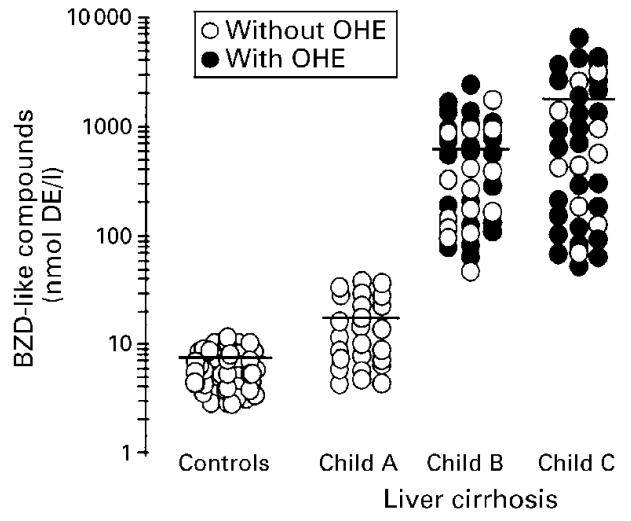

Figure 2 Serum levels of benzodiazepine (BZD)-like compounds measured by the radioligand binding technique after HPLC purification in control subjects and in liver cirrhotic patients divided according to the severity of the disease by the Child-Pugh classification. The horizontal bar represents the mean values. Kruskal-Wallis one way analysis of variance shows a significant difference between groups $(p<0.0001)$. The Mann-Whitney $U$ test adjusted using the Bonferroni correction shows that the BZD concentrations found in Pugh-Child class A patients did not differ from controls, those found in Pugh-Child class $B$ differed from those in Pugh-Child class $A(p<0.001)$, and those found in Pugh-Child class $C$ differed from those in Pugh-Child class A $(p<0.001)$ and those in Pugh-Child class $B(p<0.05)$.

precipitate plasma proteins, $1 \mathrm{ml}$ plasma was diluted with $1 \mathrm{ml}$ saline and $2 \mathrm{ml} 2 \mathrm{M}$ acetic acid, heated at $90^{\circ} \mathrm{C}$ for $10 \mathrm{~min}$ followed by the addition of $2 \mathrm{M} \mathrm{NaOH}(1 \mathrm{ml})$. After centrifugation at $20000 \mathrm{~g}$ for 20 minutes, aliquots of supernatants were lyophilised in triplicate and used for DBI radioimmunoassay (DBI-RIA). The characterisation of DBI immunoreactivity detected in serum extracts by reverse phase HPLC and the DBI-RIA, performed using antiserum produced in rabbits against human recombinant DBI, were performed as previously described. ${ }^{29} 30$

The specificity of the immunoreactive material detected was determined by incubation of different aliquots of tissue extract that paralleled the standard curve and by use of reverse phase HPLC. ${ }^{29} 31$

\section{STATISTICAL ANALYSIS}

The Kruskal-Wallis test was used to determine whether a given variable differed significantly between groups. Comparisons between single groups were performed by means of the Mann-Whitney U test corrected as described by Bonferroni.

\section{Results}

BZD-LIKE COMPOUNDS

The extraction and purification of plasma samples from normal subjects and from patients with liver cirrhosis with and without $\mathrm{OHE}$ showed the presence of at least 12 different peaks, with a retention time ranging from 17 to 70 minutes under our chromatographic conditions. The number of peaks found in each patient ranged from one to four. The number of fractions containing BZD ligands was consistently lower in controls and in liver cirrhosis without OHE (one or two peaks) than in patients with OHE (three or four peaks). 


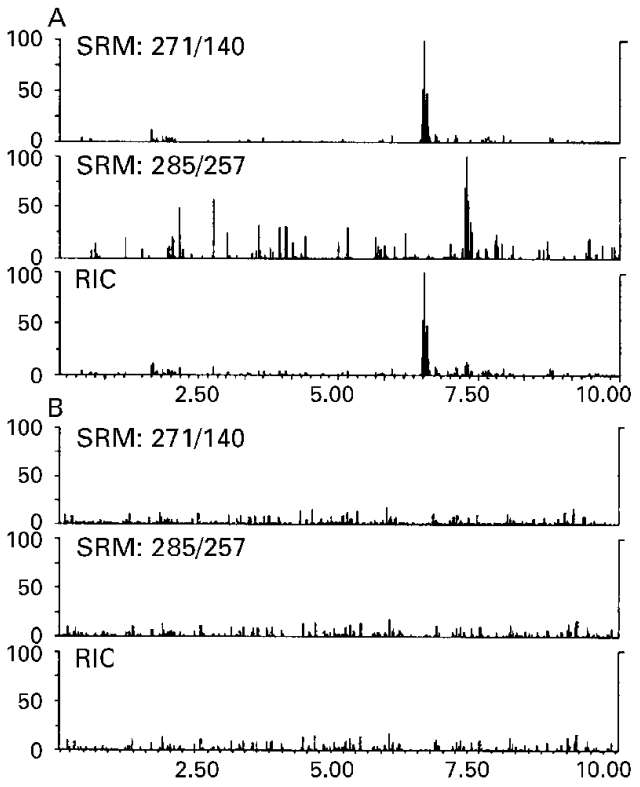

Figure 3 Mass chromatograms of serum samples from two patients $(A$ and $B)$ with stage IV hepatic encephalopathy with increased benzodiazepine-like compounds measured by the radioligand binding technique after HPLC purification. The upper panel for patient $A$ shows the presence of molecules undergoing fragmentation at $271 / 140 \mathrm{~m} / z$, which is characteristic of $N$-desmethyldiazepam, and the central panel shows the presence of molecules undergoing

fragmentation at $285 / 257 \mathrm{~m} / \mathrm{z}$, which is characteristic of diazepam, obtained by selected reaction monitoring (SRM) mass scan. The bottom panel for patient $A$ represents the reconstructed ion chromatograms (RIC) which confirms the presence of both benzodiazepines. Scanning the sample of patient $B$ for molecules with the same fragmentation patterns as above showed the absence of both benzodiazepines, and the RIC confirms this result.

The active fractions found in BZD consumers were represented by three or four peaks. The most commonly occurring peak in liver cirrhosis with OHE showed a retention time of 37 minutes, which did not correspond to the peaks of $N$-desmethyldiazepam, diazepam, lorazepam, delorazepam, 2'-chlordiazepam, or oxazepam used as standards, which respectively had retention times of $40,49,53,57,67$, and 69 minutes, under our conditions. In a few cases, $N$-desmethyldiazepam or diazepam or both were found, but the amounts normally represented less than $20 \%$ of the total BZDlike material.

The concentrations of BZDs in extracted and purified serum from normal subjects were below the limit of detection (less than $2 \mathrm{nmol}$ $\mathrm{DE} / \mathrm{l})$ in 46 cases $(51 \%)$. In the remaining 44 , the total amount of BZD substances that displaced $\left[{ }^{3} \mathrm{H}\right]$ flunitrazepam binding ranged between 6 and $20 \mathrm{nmol} \mathrm{DE} / 1$ (mean value 9.5 nmol DE/l).

In patients with liver cirrhosis, BZD-like compounds were below the limit of detection in 10 cases without OHE (16\%; eight in PughChild class A and two in Pugh-Child class B) and in five cases with OHE (7\%; four in PughChild class B and one in Pugh-Child class C).

As shown in fig 1 , the concentrations in the liver cirrhosis patients without OHE (stage 0) with measurable amounts of BZDs was extremely variable ranging from 4 to $1240 \mathrm{nmol}$ $\mathrm{DE} / \mathrm{l}$ (mean value $180 \mathrm{nmol} \mathrm{DE} / \mathrm{l}$ ). BZD concentrations in patients with stage I OHE were below the detection limit in four patients and, when measurable, ranged from 54 to 3750 nmol DE/1 (mean value $924 \mathrm{nmol} \mathrm{DE} / \mathrm{l}$ ). In patients with stage II, these compounds were below the detection limit in one patient and the others ranged from 88 to $3890 \mathrm{nmol} \mathrm{DE} / 1$ (mean value $1626 \mathrm{nmol} \mathrm{DE} / \mathrm{l}$ ). In patients with stage III, the values ranged from 98 to 3980 nmol DE/l (mean value $1348 \mathrm{nmol} \mathrm{DE} / \mathrm{l}$ ). In patients with stage IV, two patients had respectively 200 and $240 \mathrm{nmol} \mathrm{DE} / 1$ and three had 2850, 4850 and $5890 \mathrm{nmol} \mathrm{DE} / 1$ (mean value $2806 \mathrm{nmol} \mathrm{DE} / \mathrm{l})$. Kruskal-Wallis one way analysis of variance shows a significant difference between groups $(p<0.0001)$. The MannWhitney $\mathrm{U}$ test adjusted using the Bonferroni correction shows that patients without OHE (stage 0) did not differ from controls, whereas all those with OHE, irrespective of the stage, had significantly higher BZD levels than controls and patients with stage 0 OHE $(\mathrm{p}<0.001)$.

As shown in fig 1, the values found in patients with stages I, II, III, and IV of OHE were not different from each other and not different from the values found in BZD consumers, which ranged between 1400 and 5600 nmol DE/l (mean value $2511 \mathrm{nmol} \mathrm{DE} / \mathrm{l}$ ).

When the population of patients with liver cirrhosis was classified according to the ChildPugh system (fig 2), the plasma concentrations of BZDs ranged between 4 and $50 \mathrm{nmol} \mathrm{DE} / 1$ (mean value $22 \mathrm{nmol} \mathrm{DE} / \mathrm{l}$ ) in Child-Pugh class A, between 54 and $1900 \mathrm{nmol} \mathrm{DE} / 1$ (mean value $555 \mathrm{nmol} \mathrm{DE} / \mathrm{l}$ ) in Child-Pugh class B, and between 82 and $5890 \mathrm{nmol} \mathrm{DE} / 1$ (mean value $1739 \mathrm{nmol} \mathrm{DE} / \mathrm{l}$ ) in Child-Pugh class C. Kruskal-Wallis one way analysis of variance shows a significant difference between groups $(\mathrm{p}<0.0001)$. The Mann-Whitney U test adjusted using the Bonferroni correction shows that the BZD concentrations found in PughChild class A patients did not differ from controls, those found in Pugh-Child class B patients differed from Pugh-Child class A $(\mathrm{p}<0.001)$, and those found in Pugh-Child class C differed from Pugh-Child class A $(p<0.001)$ and from Pugh-Child class B $(p<0.05)$, indicating a correlation between serum BZD concentrations and the severity of the liver disease.

DETERMINATION OF 1,4-BENZODIAZEPINES BY HPLC-ESI-MS-MS (FIG 3)

Mass spectrometric studies utilising HPLCESI-MS-MS on the active fractions were performed on 12 controls, 37 liver cirrhosis cases without $\mathrm{OHE}$, and 16 liver cirrhosis cases with stages I-IV of OHE. Diazepam and $N$-desmethyldiazepam were below the detection limit in normal subjects and in 34 of 37 of the patients without OHE. In the remaining three patients, trace amounts of both compounds were found in two, and in one there was only $\mathrm{N}$-desmethydiazepam. In liver cirrhosis with OHE the above two compounds were below the detection limit in two patients with stage I OHE and were represented only in trace amounts of $N$-desmethyldiazepam in two patients with stage III and IV OHE 


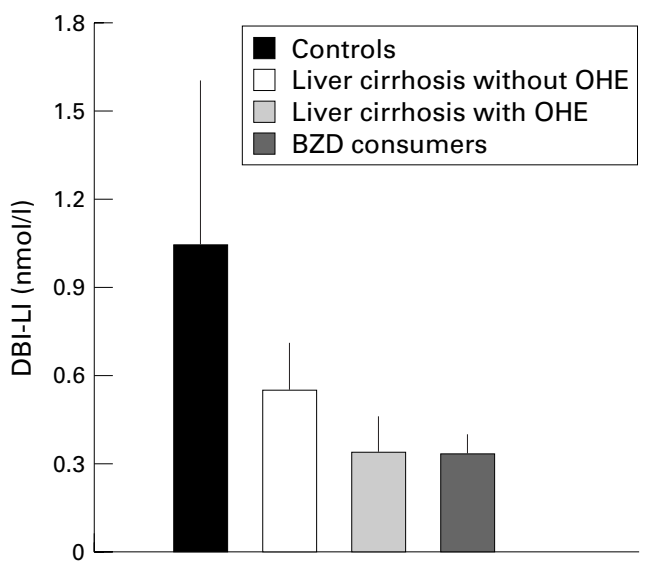

Figure 4 Plasma levels (mean (SD)) of diazepam binding inhibitor-like immunoreactivity (DBI-LI) in control subjects, in liver cirrhotic patients without overt hepatic encephalopathy (OHE), in patients with different stages of OHE, and in benzodiazepine (BZD) consumers. Kruskal-Wallis one way analysis of variance shows a significant difference between groups $(p<0.0001)$. The $M a n n-W h i t n e y U$ test adjusted using the Bonferroni correction shows that the levels found in liver cirrhotic patients with or without OHE were statistically different from controls $(p<0.05$ and $p<0.001$ respectively). The $D B I-L I$ in BZD consumers was different from controls $(p<0.005)$ and practically equal to those found in cirrhotic patients with or without $O H E$.

respectively. In the remaining 12 patients the values for $N$-desmethyldiazepam ranged between 94 and $835 \mathrm{nmol} / 1$ and those for diazepam ranged between 45 and $112 \mathrm{nmol} / \mathrm{l}$, and there was no correlation with the stage of OHE. Figure 3 shows the reconstructed ion chromatograms of plasma samples from two patients with liver cirrhosis and stage IV OHE.

DIAZEPAM BINDING INHIBITOR (FIG 4)

The DBI-LI levels ranged between 0.31 and $2.37 \mathrm{nmol} / 1$ (mean value $1.04 \mathrm{nmol} / \mathrm{l}$ ) in control subjects, between 0.28 and $1.01 \mathrm{nmol} / 1$ (mean value $0.55 \mathrm{nmol} / \mathrm{l}$ ) in liver cirrhosis without OHE, and between 0.13 and 0.57 $\mathrm{nmol} / \mathrm{l}$ (mean value $0.34 \mathrm{nmol} / \mathrm{l}$ ) in liver cirrhosis with OHE. Interestingly, the levels of DBI-LI in BZD consumers ranged between 0.15 and $0.57 \mathrm{nmol} / 1$ (mean value 0.33 $\mathrm{nmol} / \mathrm{l}$ ). Kruskal-Wallis one way analysis of variance shows a significant difference between groups $(\mathrm{p}<0.0001)$. The Mann-Whitney U test adjusted using the Bonferroni correction shows that the levels found in liver cirrhotic patients with or without OHE were statistically different from controls $(\mathrm{p}<0.05$ and $\mathrm{p}<0.001$ respectively). The DBI-LI in BZD consumers was different from controls $(p<0.005)$ and similar to those found in cirrhotic patients with or without OHE.

\section{Discussion}

We have shown in this study, which includes a large number of fully characterised liver cirrhotic patients, that: (1) endogenous BZDlike compounds are, under our experimental conditions, below the detection limit ( $2 \mathrm{nmol}$ $\mathrm{DE} / \mathrm{l})$ in $51 \%$ of normal subjects, in $16 \%$ of liver cirrhotic patients without $\mathrm{OHE}$, and in $7 \%$ of those with OHE; (2) when detectable, BZD levels rise in the serum of cirrhotic patients in correlation with worsening liver function, but not with the degree of OHE; (3) the measurable BZD-like compounds comprise both known BZDs such as diazepam and $N$-desmethyldiazepam and unknown BZD-like compounds, and these so called "endozepines" seem to represent most of the displacing ligands in plasma; (4) when detectable, the BZD levels found in patients with OHE were comparable with those present in BZD consumers with normal states of consciousness; (5) DBI-LI levels were found to be decreased in cirrhotic patients independently of the presence or absence of OHE. In BZD consumers, in whom BZD levels were constantly elevated, we found a significant reduction of DBI-LI. These data indicate an inverse correlation with the levels of circulating BZDs.

The finding that encephalopathy may occur in liver cirrhotic patients with very low levels of circulating BZD-like compounds, if not below the detection limit, is in line with the results of previous studies on patients with OHE due to fulminant hepatic failure. In these studies, only $60 \%$ of patients showed increased levels of BZDs in serum ${ }^{1}$ and only $55 \%$ had increased concentrations in the brain. ${ }^{12}$ These findings are in line with the concept that BZDs in serum diffuse passively into the brain and are in equilibrium with BZDs in the brain. ${ }^{32} 33$

The finding that, when detectable, circulating BZD-like compounds reach concentrations comparable with those found in BZD consumers raises the question of what causes the difference in the response to BZDs by the brains of cirrhotic patients with OHE and those of BZD consumers.

Chronic exposure to commercial BZD produces tolerance represented by reduced GABA-BZD receptor function; this means that administration of increased doses of the drug is required to maintain the pharmacological effect. $^{33}$ In contrast, in patients with liver cirrhosis, rather than tolerance, there is increased cerebral sensitivity to BZD administration. It has been shown that the reduction in BZD dose requirements in these patients is due to changes in the cerebral sensitivity more than to changes in drug disposition. ${ }^{33}{ }^{34}$ Hence it seems fair to surmise that the enhanced GABAergic tone cannot be attributed to increased endogenous BZD-like compounds per se, but more to the presence of pre-existing brain dysfunction related, for example, to ammonia toxicity. ${ }^{1316}$ In this situation, a concentration of circulating BZD-like compounds that would have no effect in a normal subject may facilitate sedation and worsen an episode of encephalopathy in a liver cirrhotic patient.

Finally, as regards the nature of the BZD-like compounds in serum, we found the presence of both diazepam and $N$-desmethyldiazepam by HPLC-ESI-MS-MS analysis. These halogenated compounds, however, represented less than $20 \%$ of the total BZD receptor ligands. This observation, which confirms the results of previous studies, ${ }^{8-10}$ indicates that most of these compounds are substances of unknown origin and nature called "endozepines". ${ }^{9}$ Both 
halogenated and non-halogenated BZDs were found inconsistently in patients with OHE and were sometimes not raised at all.

It remains, however, unclear why BZDs accumulate in the blood of some liver cirrhotic patients and not in others with the same pathological condition. Retrospective control of the diet and therapy used in our patients as well as establishment of the aetiology of the liver cirrhosis did not show any substantial difference to explain this phenomenon.

As regards DBI, we found that the levels of this peptide are significantly decreased in those patients with liver cirrhosis and increased levels of BZDs independently of the presence or absence of OHE. The levels of DBI do not correlate with neuronal dysfunction or the severity of the liver disease. This finding would appear to exclude any direct effect of the liver dysfunction and the encephalopathy on the metabolism of this circulating peptide and suggests the presence in the periphery of a negative regulatory feedback mechanism exerted by BZDs on DBI. Accordingly, the same decrease is present in BZD consumers. The relation between DBI levels in plasma and those in the central nervous system is still poorly understood, as is also the regulation of its synthesis and metabolism in peripheral tissues. From these data we can surmise that the ratio between DBI and BZDs in the periphery is probably regulated by different mechanisms from those operating in the central nervous system. In liver cirrhotic patients with $\mathrm{OHE}$, in fact, DBI was shown to be increased in cerebrospinal fluid in the presence of increased levels of BZDs, and the phenomenon was interpreted as an episode of compensatory reaction by DBI to an increased presence of BZDs. $^{23}$

Whatever the regulatory mechanism in the periphery may be, the described decrease in DBI in the blood of the liver cirrhotic patients may be of relevance from the metabolic point of view, since this peptide, through stimulation of peripheral $\mathrm{BZD}$ receptors, regulates the intermediate metabolism and steroid biosynthesis. ${ }^{22} 35$

In conclusion, endogenous compounds with sedative action may accumulate in patients with liver cirrhosis during the course of the disease, and the phenomenon appears to be independent of the presence or absence of encephalopathy. The observation that circulating BZD-like compounds reach levels comparable with those found in BZD consumers with a normal state of consciousness reinforces the concept that these compounds may be more effective in those patients with pre-existing altered brain function. ${ }^{33} 34$

This work was supported by a grant from MIRAAF (no 7240 1993. Rome) and a grant from Modena University. We thank Professor H Alho, University of Tampere, Finland who kindly provided antiserum raised in rabbits against human recombinant DBI. Preliminary data on the assay performed with the radioligand binding technique without previous HPLC purification were given as an oral presentation to the Internationa Association for the Study of the Liver, Cancun, May 1994, and published in abstract form: Zeneroli ML, Venturini I, Avallone R, Ardizzone G, Demartini M, Portella G, Baraldi M. Levels of endogenous benzodizepine-like compounds in serum of liver cirrhosis patients with and without encephalopathy and in fulminant hepatic failure. Hepatology 1994;19:1431
1 Zeneroli ML. Hepatic encephalopathy. Experimental studes in a rat model of fulminant hepatic failure. 7 Hepatol $1985 ; 1: 301-12$

2 Jones EA, Skolnick P, Gammal H, et al. The gammaaminobutyric acid-A (GABA-A) receptor complex and hepatic encephalopathy. Some recent advances. Ann Intern Med 1989;110:532-46.

3 Baraldi M. Supersensitivity of GABA-A receptors in hepatic encephalopathy. Neurochem Res 1990;15:153-60.

4 Baraldi M, Zeneroli ML, Ventura E, et al. Supersensitivity of benzodiazepine receptors in hepatic encephalopathy due to fulminant hepatic failure in the rat: reversal by benzodiazepine antagonist. Clin Sci 1984;67:167-75.

5 Scollo-Lavizzari G, Steinmann E. Reversal of hepatic coma by benzodiazepine antagonist (Ro 15-1788). Lancet 1985; 1:1324.

6 Bansky G, Meier PJ, Ziegler WH, et al. Reversal of hepatic coma by benzodiazepine antagonist (Ro 15-1788). Lancet 1985;1:1324-5

7 Olasmaa M, Guidotti A, Costa E, et al. Endogenous benzodiazepines in hepatic encephalopathy. Lancet 1989;1:491-

8 Basile AS, Gammal SH, Jones EA, et al. GABA-A receptor complex in an experimental model of hepatic encephalopathy: evidence for elevated levels of an endogenous benzodiazepine receptor complex ligand. 7 Neurochem 1989;53:1057-63.

9 Olasmaa M, Rothstein JD, Guidotti A, et al. Endogenous benzodiazepine in human and animal hepatic encephalopathy. F Neurochem 1990;55:2015-23.

10 Mullen KD, Szauter KM, Kaminsky-Russ K. "Endogenous" benzodiazepine activity in body fluids of patients with hepatic encephalopathy. Lancet 1990;336:81-3.

11 Baraldi M, Zeneroli ML, Rothstein JD, et al. Increased presence of benzodiazepine-like compounds in a rat model of hepatic encephalopathy. In: Bengtsson F, Jeppson B, eds. Progress in hepatic encephalopathy. Miami: CRC Press, 1991 .
155-60.

2 Basile AS, Hughes RD, Harrison PH, et al. Elevated brain concentrations of 1,4-benzodiazepines in fulminant hepatic concentrations of 1,4-benzodiazepines

13 Basile AS, Harrison PM, Hughes RD, et al. Relationship between plasma benzodiazepine receptor ligand concentrations and severity of hepatic encephalopathy. Hepatology 1994;19:112-21

14 Mullen KD, Martin JV, Mendelson WB, et al. Could an endogenous benzodiazepine ligand contribute to hepatic encephalopathy? Lancet 1988;1:457-9.

15 Baraldi M, Pinelli G, Ricci P, et al. Toxins in hepatic encephalopathy: the role of the synergistic effect of ammonia, mercaptans and short chain fatty acids. Arch Toxicol 1984;7(suppl): 103-5.

16 Itzhah Y, Norenberg MD. Ammonia-induced up-regulation of peripheral-type benzodiazepine receptors in cultured
astrocytes labeled with $\left[{ }^{3} \mathrm{H}\right] \mathrm{PK} 11195$. Neurosi Lett 1994; astrocytes

17 Basile AS, Jones EA. Ammonia and GABAergic neurotransmission: interrelated factors in the pathogenesis of hepatic encephalopathy. Hepatology 1997;25:1303-5.

18 Medina JH, Pena C, Levi de Stein M, et al. Benzodiazepinelike molecules as well as other ligands for the brain benzodiazepine receptors, are relatively common constituents of plants. Biochem Biophys Res Commun 1989;165:547-53.

19 Sangameswaran L, De Blas AL. Demonstration of the benzodiazepine-like molecules in the mammalian brain with a monoclonal antibody to benzodiazepines. Proc Natl Acad Sci USA 1985;82:5560-4.

20 De Blas AL, Park D, Friedrich P. Endogenous benzodiazepine-like molecules in human, rat and bovine brains studied with a monoclonal antibody to benzodiazepines. Brain Res 1987;413:275-84.

21 Zeneroli ML, Venturini I, Stefanelli S, et al. Antibacterial activity of rifaximin reduces the levels of benzodiazepinelike compounds in patients with liver cirrhosis. Pharmacol Res 1997;35:557-60.

22 Guidotti A, Forchetti CM, Corda MG, et al. Isolation, characterization and purification to homogeneity of an endogenous polypeptide with agonistic action on benzodi5.

Rothstein JD, Mckhann G, Guarnieri P, et al. Cerebrospinal fluid content of diazepam binding inhibitor (DBI) in chronic hepatic encephalopathy. Ann Neurol 1989;26:5762 .

24 Butterworth RF, Tonon MC, Desy L, et al. Increased brain content of the endogenous benzodiazepine receptor ligand, octadecaneuropeptide (ODN), following portacaval anastomosis in the rat. Peptides 1991;12:119-25.

25 Kennedy J, Parbhoo SP, MacGilivray B, et al. Effect of extracorporeal liver perfusion on the electroencephalogram of patients in coma due to acute liver failure. $Q \mathcal{F}$ Med 1973;42:549-61.

26 Pugh RNH, Murray-Lyon IM, Dawson JL, et al. Transection of the oesophagus for bleeding oesophageal varices. $\mathrm{Br}$ 7 Surg 1973;60:646-9.

27 Bradford MM. A rapid and sensitive method for the quantitation of microgram quantities of protein utilizing the principle of protein-dye binding. Anal Biochem 1976;72:24854.

28 Kleinschnitz M, Herderich M, Schreier P. Determination of 1,4-benzodiazepines by high-performance liquid chromatography-electrospray tandem mass spectrometry. $\mathcal{F}$
Chromatogr B Biomed Appl 1996;676:61-7. 
29 Ferrarese C, Apollonio L, Frigo M, et al. Cerebrospinal fluid levels of diazepam-binding inhibitor in neurodegenerative levels of diazepam-binding inhibitor in neurodegen
disorders with dementia. Neurology 1990;40:632-5.

30 Ferrarese C, Appollonio I, Frigo M, et al. Distribution of a putative endogenous modulator of the GABAergic system in human brain. Neurology 1989;39:443-5.

31 Kolmer M, Pelto-Huikko M, Alho H. Germ-cell specific transcription of the diazepam binding inhibitor (DBI) gene in testis: evidence for translational control. DNA Cell Biol 1997;16:59-72.

32 Greenblatt DJ, Miller LG, Shader RI. Neurochemical and pharmacokinetic correlates of the clinical action of benzo-
diazepine hypnotic drugs. Am $\mathcal{F}$ Med 1990;88:194-236.
33 Branch RA, Morgan MH, James J, et al. Intravenous administration of diazepam in patients with chronic liver disease. Gut 1976;17:975-83.

34 Baktir GA, Fisch HU, Karlaganis G, et al. Mechanism of the excessive sedative response of cirrhotics to benzodiazepine: model experiments with triazolam. Hepatology 1987;7:62938.

35 Papadopoulos V, Berkovich A, Krueger KE, et al. Diazepam binding inhibitor and its processing products stimulate mitochondrial steroid biosynthesis via an interaction with mitochondrial benzodiazepine receptors. Endocrinology 1991;129:1481-7. 